\title{
Methotrexate in Rheumatoid Arthritis: Efficacy and Safety
}

\section{Bird $\mathbf{P}^{*}$, Griffiths $\mathbf{H}$ and Littlejohn $\mathbf{G}$}

On behalf of the OPAL Research Group

*Corresponding author: Paul Bird, Combined Rheumatology Practice, Suite 4, Level 1, 19 Kensington St., Kogarah, New South Wales, 2217, Australia., Tel: 02 95870238; E-mail: pbird@optimusresearch.com.au

Rec Date: Dec 17, 2013, Acc Date: March 10, 2014, Pub Date: March 17, 2014

Copyright: $\odot 2014$ Bird P, et al. This is an open-access article distributed under the terms of the Creative Commons Attribution License, which permits unrestricted use, distribution, and reproduction in any medium, provided the original author and source are credited.

\section{Abstract}

Methotrexate is the mainstay of treatment in rheumatoid arthritis (RA). Used for over 40 years as an anchor treatment in a number of rheumatic diseases, it remains a gold standard of therapy for RA. This review will provide a concise discussion of the efficacy and safety of methotrexate in rheumatic disease, with a focus on Rheumatoid Arthritis.

Keywords: Methotrexate; Optimal Dosing; Rheumatoid Arthritis Efficacy

\section{Part 1: Efficacy, Mechanism of Action, Optimal Dosing}

\section{History}

The first reported use of Methotrexate (MTX) in 1951 [1] was an unnoticed event, but it would herald the beginnings of the acceptance of MTX as conventional therapy for rheumatic disease. Thirty years would elapse after this initial account before MTX use in rheumatology became commonplace. Eventually, however, the use of MTX has become standard therapy in rheumatic disease [2].

Even today, despite the advent of complex biologic agents for the treatment of rheumatic diseases, MTX remains an anchor therapy, used as a first line agent in a majority of patients.

\section{Mechanism of action}

The precise mechanism of MTX in treating rheumatic disease is uncertain. The most widely accepted theory is that MTX prevents de novo pyrimidine and purine synthesis, and therefore inhibits lymphocyte proliferation [3]. Other putative mechanisms include increased apoptosis of T cells [4], alteration of expression of cellular adhesion molecules [5], increased release of the endogenous antinflammatory adenosine [6], reduction in expression of cellular adhesion molecules [7], and anti-angiogenesis effects via indirect mechanisms such as disruption of macrophage interaction. The key message is that MTX likely acts via multiple pathways in RA, with no single mechanism of action, perhaps explaining the drug's effectiveness in patients with different phenotypes.

\section{Efficacy in Rheumatoid Arthritis}

The efficacy of MTX in RA is well established. In addition to reducing signs and symptoms of the disease, MTX therapy has been shown to reduce radiographic progression of joint damage, improve quality of life outcomes, and reduce mortality [8-11].

Of interest, MTX in combination with anti- TNF agents appears to be more effective than monotherapy with anti-TNF therapy [12-14]. This reinforces the notion that while newer biologic therapies are highly effective in treating RA, the role of MTX remains as an anchor therapy in many patients.

\section{Methotrexate dosing}

Despite the widespread use of MTX in RA, there is considerable variability in the way that rheumatologists prescribe MTX therapy, including dose and route of administration.

Three pivotal RCT studies have directly compared the efficacy of different oral MTX doses. These studies represent the best available data comparing doses of MTX in RA, with the primary outcome measures of efficacy and safety.

Furst et al. compared start doses of 5-10 mg weekly, $12.5-20 \mathrm{mg}$ weekly and 25-35 mg weekly versus placebo [15] in RA of long duration who failed other Disease Modifying Antirheumatic Drugs (DMARDs). The study confirmed MTX 12.5-20 mg weekly had a significantly larger effect than placebo or lower dose on tender joint count (TJC), pain, and global status. Dose toxicity was noted with gastrointestinal (GI) and mucocutaneous toxicity highest in the 22-35 mg weekly group. In this study, radiologic outcomes were not reported.

In the study reported by Schnabel et al. [16], a start dose of 15-25 mg weekly was evaluated, with increases or decreases dependent on response and/or toxicity. These patients were of long disease duration, with characteristics similar to the Furst cohort. The authors reported that $27 \%$ of patients beginning at $15 \mathrm{mg}$ weekly required an increase in dose to improve efficacy, compared with only $3 \%$ of patients who began at $25 \mathrm{mg}$ weekly. There was no difference in toxicity between the groups.

The Verstappen et al. [17] evaluated a DMARD naïve, early RA cohort using a rapid escalation strategy versus slow escalation strategy. In the first group, start dose was $7.5 \mathrm{mg}$ weekly and then increasing by $5 \mathrm{mg}$ per month to a mean maximum of $25 \mathrm{mg}$ weekly. In the slow escalation group, MTX was increased by $5 \mathrm{mg}$ every 3 months to a mean maximum of $18 \mathrm{mg}$ weekly. More patients in the fast escalation group achieved ACR 50 response with overall better improvements in TJC, swollen joint count (SJC), pain, global status. Adverse events (AEs) were similar in characteristics in both groups (Odds Ratio (OR) 2.3 for fast versus slow dose escalation). No additional effect was noted 
Page 2 of 4

with respect to $\mathrm{x}$-ray progression in the fast versus slow dose escalators.

Parenteral MTX is purported to produce superior response and fewer side effects. The data to support these statements is limited. An early study evaluating parenteral administration used a switch from oral MTX $15 \mathrm{mg}$ weekly to subcutaneous (SC) MTX $15 \mathrm{mg}$ weekly, showing a slight increase in ACR 20 response (85\% versus 77\%) [18]. Toxicity was higher in the SC group with more patients withdrawn due to AEs.

Based on these studies, an international consensus group [19] has recommended a start dose of $15 \mathrm{mg}$ weekly orally, escalating $5 \mathrm{mg}$ per month to $25-30 \mathrm{mg}$ weekly as tolerated, and with consideration of switch to SC dosing if response is inadequate.

These recommendations represent a realistic approach, based upon the best available evidence.

\section{Part 2: Safety}

Concerns regarding the safety of MTX in rheumatic disease need to be placed in the context of a risk-benefit analysis. The remainder of this review will address the common and rare side effects associated with low dose weekly MTX, attempting to place these in a commonsense framework.

\section{Frequent, reversible and minor adverse effects}

\section{Neurological}

Cognitive side effects include lethargy, impaired concentration and headache. These side effects may limit therapy escalation and can be assisted by folic acid supplementation. The neurotoxicity of MTX may be related to the accumulation of adenosine due to the inhibition of purine synthesis [20].

The effects are reversible, resolving with dose reduction or cessation.

\section{Gastrointestinal}

The major side effects in this category are mucositis, mouth ulceration, nausea and diarrhea. These are not common, usually precluded by the adequate use of folic acid supplementation [21], and resolve with reduction or cessation of therapy. The effects tend to occur during the initial phases of therapy, often during the 24-48 hours post dose. Most of these effects will resolve with continuing therapy but if the side effects are dose limiting or disabling, treatment should be reassessed.

\section{Nodulosis}

An uncommon side effect, seen with reduced frequency as treatment becomes more intensive and extra-articular manifestations of RA become less frequent. Nevertheless, MTX can certainly increase the occurrence of nodules, perhaps related to adenosine accumulation and enhancement of giant cell formation [22].

\section{More serious effects, less common}

\section{Hepatotoxicity}

Reversible transaminase elevation, liver fibrosis and liver cirrhosis are the three possible hepatic side effects of weekly low dose MTX. In practical terms, reversible transaminase elevation is most common with fibrosis and cirrhosis regarded as rare occurrences, more likely to occur in the presence of risk factors such as excessive alcohol consumption or pre-existing liver disease. Transaminase monitoring is mandatory in all patients on low dose MTX with dose lowering or cessation dependent on the level of transaminase elevation.

Registry data has provided new insights into the frequency of transaminase abnormalities in cohorts taking low dose MTX for RA. The CORRONA data registry conducted a review of patients taking MTX as monotherapy or MTX and Leflunomide (LEF), a synthetic DMARD with potential liver toxicity. The two drugs are commonly used together to control active RA disease. Amino-transfersase (ALT) elevation was recorded in $31.5 \%$ of patients in the combination group compared with $6.8 \%$ in the MTX monotherapy group [23]. The majority of the elevations $(21.5 \%)$ were $<2$ times the upper limit of normal. AST elevation was noted in $16.9 \%$ of patients compared with $4.6 \%$ in the placebo group. The majority $(16 \%)$ were $<2$ times the upper limit of normal.

The CORRONA registry data was used to establish odds ratio (OR) for the development of LFT abnormalities with MTX monotherapy or with the MTX/ LEF combination.

The OR was predominantly dependent on the MTX dose (and not on the DMARD combination). At a dose of LEF $20 \mathrm{mg}$ per day, in combination with MTX $7.5 \mathrm{mg}$, the OR for developing liver abnormalities was 2.15, increasing to an OR of 3.98 if a dose of MTX at $20 \mathrm{mg}$ weekly was used.

Data from the Safety of Methotrexate and Leflunomide in RA trial (SMILE) examined a cohort of 2975 patients collating data on transaminase abnormalities over a 12 month period [24]. Patients received the following therapies: MTX monotherapy 52.2\% $(\mathrm{n}=1552)$, LEF monotherapy 7.3\% $(\mathrm{n}=217)$, MTX plus LEF $13.9 \%(\mathrm{n}=415)$, and neither MTX nor LEF 26.6\% ( $\mathrm{n}=791)$. The mean MTX dose was 14.6 mg weekly (standard deviation [SD] 9.1) in the monotherapy group and $15.4 \mathrm{mg}$ (SD 5.9) in the MTX/LEF combination group. Transaminase abnormalities were reported in $12 \%(n=186)$ of patients in the MTX monotherapy group, $16 \%(n=35)$ in the LEF monotherapy group, $19 \%(n=79)$ in the MTX/LEF combination group and $14 \%$ $(n=109)$ in the group taking neither medication. There were no reports of liver fibrosis or cirrhosis. MTX and/or LEF cessation due to AEs were recorded in only a minority of patients.

The results from both large cohorts are reassuring and reinforce the notion that serious liver abnormalities in patients using low dose MTX are rare. Transaminase abnormalities can be regarded as low in frequency and usually resolve with dose reduction or cessation of MTX if this is deemed to be the cause.

\section{Hematological abnormalities}

Neutropenia and lymphopenia are the commonest abnormalities encountered in RA. With the reduction in incidence of extra-articular manifestations, such as Felty's syndrome, thrombocytopenia has become uncommon. 
Page 3 of 4

Pancytopenia in patients taking MTX for treatment of RA is well reported. At risk patients include the elderly, [25] those with concomitant use of dihydrofolate reductase inhibitors [26], and patients with renal impairment [27].

In the cross sectional study published by our group, across all treatment groups, neutropenia as defined by a neutrophil count of $<$ $2.0 \times 10^{9} / \mathrm{L}$, was reported in $2.3 \%$ of the MTX monotherapy group, $5.5 \%$ of the LEF monotherapy group, $3.9 \%$ of the MTX/LEF combination group and $4.2 \%$ of the group taking neither drug. It is interesting to note that the rate of neutropenia was higher in patients not taking MTX, than those taking MTX as monotherapy. Additionally, these values did not correspond to an increased incidence of infection.

The data is reassuring. A full blood count should remain as a monitoring tool in patients taking low dose MTX for RA, but reduction of the neutrophil count is very uncommon.

\section{Pulmonary abnormalities}

Lung disease associated with MTX therapy, either alone or in combination with other drugs is a well-recognized but rare complication $(0.08 \%$ of treated patients) of therapy [28]. Factors contributing to the risk of MTX- induced lung injury include preexisting interstitial lung diseases (ILD), cigarette smoking, and low body weight [29].

\section{Intercurrent infection risk}

It has long been recognized that patients with RA have a higher risk of infection. Case control studies comparing RA cohorts with healthy populations show an increased risk of infection (positive microbial results or imaging) in RA patients (19.6/100 person years compared with 12.8/100 person years in healthy controls) [30]. The most common infections occur in the broncho-pulmonary and urinary tract [31].

In this context, low dose weekly MTX can be considered an immunosuppressive, but the question is whether MTX is associated with an increased risk of typical or atypical infections. To this end the data is conflicting in part due to the inclusion of long term cohorts with severe disease in analyses [32]. In other cohorts, steroids appear to demonstrate a higher risk of infection compared with MTX [33] and several large cohorts have not demonstrated a clear relationship between MTX and increased infection risk [34-36].

Atypical infections have been linked to low dose MTX in case reports but these cases appear to be isolated, associated with comorbidities and not common in clinical practice.

Overall, low dose MTX does not appear to increase infection risk in patients with RA. Disease severity, use of corticosteroids and comorbidities are important factors, recognizing that RA patients have an intrinsic increased risk of infection compared with the general population.

\section{Long term use and malignancy}

Incidence of cancer and mortality by cancer are slightly higher in RA cohorts compared with the general population $[38,39]$. In particular a slightly increased risk of haematopoietic and lung cancer has been noted [40].
Drug therapy in patients with RA does appear to increase this risk although caution should be used in interpreting this data given the increased background incidence in RA patients.

In a Canadian study of 23,810 patients with RA, spanning years 1980-2003, hematologic malignancies was found to be developed in 619 patients (including lymphoma in 346, leukemia in 178 and myeloma in 95). Analysis was performed to assess the effect of DMARD therapy. The analysis showed the unadjusted ratios for hematologic malignancy after drug exposures were: MTX 1.18 (95\% CI 0.99-1.40), Azathioprine $1.44 \quad(95 \% \quad \mathrm{CI} \quad 1.01-2.03)$ and cyclophosphamide 2.21 (95\% CI, 1.52-3.20) [41].

The data are reassuring for MTX. Whilst there is an increase in risk, this remains at a low level.

\section{Summary}

Weekly low dose MTX provides an efficacious, cost effective, generally well tolerated treatment for RA. Physicians must be aware of the risks associated with its use and monitor accordingly.

\section{References}

1. Gubner R, August S, Ginsberg V (1951) Effect of aminopterin in rheumatoid arthritis and psoriasis. Am J Med Sci 221: 176-82

2. Weinblatt ME, Coblyn JS, Fox DA, Fraser PA, Holdsworth DE, et al. (1985) Efficacy of low-dose methotrexate in rheumatoid arthritis. N Engl J Med 312: 818-822.

3. Wessels JA, Huizinga TW, Guchelaar HJ (2008) Recent insights in the pharmacological actions of methotrexate in the treatment of rheumatoid arthritis. Rheumatology (Oxford) 47: 249-255.

4. Quéméneur L, Gerland LM, Flacher M, Ffrench M, Revillard JP, et al. (2003) Differential control of cell cycle, proliferation, and survival of primary $\mathrm{T}$ lymphocytes by purine and pyrimidine nucleotides. J Immunol 170: 4986-4995.

5. Miranda-Carús ME, Balsa A, Benito-Miguel M, Pérez de Ayala C, Martín-Mola E (2004) IL-15 and the initiation of cell contact-dependent synovial fibroblast-T lymphocyte cross-talk in rheumatoid arthritis: effect of methotrexate. J Immunol 173: 1463-1476.

6. Montesinos MC, Desai A, Delano D, Chen JF, Fink JS, et al. (2003) Adenosine $\mathrm{A} 2 \mathrm{~A}$ or $\mathrm{A} 3$ receptors are required for inhibition of inflammation by methotrexate and its analog MX-68. Arthritis Rheum 48: 240-247.

7. Bunescu A, Seideman P, Lenkei R, Levin K, Egberg N (2004) Enhanced Fcgamma receptor I, alphaMbeta2 integrin receptor expression by monocytes and neutrophils in rheumatoid arthritis: interaction with platelets. J Rheumatol 31: 2347-2355.

8. Hanrahan PS, Scrivens GA, Russell AS (1989) Prospective long term follow-up of methotrexate therapy in rheumatoid arthritis: toxicity, efficacy and radiological progression. Br J Rheumatol 28: 147-153.

9. Weinblatt ME, Maier AL, Fraser PA, Coblyn JS (1998) Longterm prospective study of methotrexate in rheumatoid arthritis: conclusion after 132 months of therapy. J Rheumatol 25: 238-242.

10. Bologna C, Viu P, Picot MC, Jorgensen C, Sany J (1997) Long-term follow-up of 453 rheumatoid arthritis patients treated with methotrexate: an open, retrospective, observational study. Br J Rheumatol 36: 535-540.

11. Rau R, Schleusser B, Herborn G, Karger T (1997) Long-term treatment of destructive rheumatoid arthritis with methotrexate. J Rheumatol 24: 1881-1889.

12. van der Heijde D, Klareskog L, Rodriguez-Valverde V, Codreanu C, Bolosiu H, et al. (2006) Comparison of etanercept and methotrexate, alone and combined, in the treatment of rheumatoid arthritis: two-year clinical and radiographic results from the TEMPO study, a double-blind, randomized trial. Arthritis Rheum 54: 1063-1074. 
13. Breedveld FC, Weisman MH, Kavanaugh AF, Cohen SB, Pavelka K, et al. (2006) The PREMIER study: A multicenter, randomized, double-blind clinical trial of combination therapy with adalimumab plus methotrexate versus methotrexate alone or adalimumab alone in patients with early, aggressive rheumatoid arthritis who had not had previous methotrexate treatment. Arthritis Rheum 54: 26-37.

14. Smolen JS, Han C, Bala M, Maini RN, Kalden JR, et al. (2005) ATTRACT Study Group. Evidence of radiographic benefit of treatment with infliximab plus methotrexate in rheumatoid arthritis patients who had no clinical improvement: a detailed subanalysis of data from the anti-tumor necrosis factor trial in rheumatoid arthritis with concomitant therapy study. Arthritis Rheum 52: 1020-1030.

15. Furst DE, Koehnke R, Burmeister LF, Kohler J, Cargill I (1989) Increasing methotrexate effect with increasing dose in the treatment of resistant rheumatoid arthritis. J Rheumatol 16: 313-320.

16. Schnabel A, Reinhold-Keller E, Willmann V, Gross WL (1994) Tolerability of methotrexate starting with 15 or $25 \mathrm{mg} /$ week for rheumatoid arthritis. Rheumatol Int 14: 33-38

17. Verstappen SM, Jacobs JW, van der Veen MJ, Heurkens AH, Schenk Y, et al. (2007) Intensive treatment with methotrexate in early rheumatoid arthritis: aiming for remission. Computer Assisted Management in Early Rheumatoid Arthritis (CAMERA, an open-label strategy trial). Ann Rheum Dis 66: 1443-1449.

18. Braun J, Kästner P, Flaxenberg P, Währisch J, Hanke P, et al. (2008) Comparison of the clinical efficacy and safety of subcutaneous versus ora administration of methotrexate in patients with active rheumatoid arthritis: results of a six-month, multicenter, randomized, double-blind, controlled, phase IV trial. Arthritis Rheum 58: 73-81.

19. Visser K, Katchamart W, Loza E, Martinez-Lopez JA, Salliot C, et al. (2008) Multinational evidence based recommendations for the use of Methotrexate in rheumatic disorders with a focus on rheumatoid arthritis: integrating systematic literature and expert opinion of a broad international panel of rheumatologists in the 3E initiative. Ann Rheum Dis 68: 1086-1093.

20. Quinn CT, Kamen BA (1996) A biochemical perspective of methotrexate neurotoxicity with insight on nonfolate rescue modalities. J Investig Med 44: 522-530.

21. Ortiz Z, Shea B, Suarez-Almazor ME, Moher D, Wells GA, et al. (1998) The efficacy of folic acid and folinic acid in reducing methotrexate gastrointestinal toxicity in rheumatoid arthritis. A metaanalysis of randomized controlled trials. J Rheumatol 25: 36-43.

22. Merrill JT, Shen C, Schreibman D, Coffey D, Zakharenko O, et al. (1997) Adenosine A1 receptor promotion of multinucleated giant cell formation by human monocytes: a mechanism for methotrexate-induced nodulosis in rheumatoid arthritis. Arthritis Rheum 40: 1308-1315.

23. Curtis JR, Beukelman T, Onofrei A, Cassell S, Greenberg JD, et al. (2010) Elevated liver enzyme tests among patients ?with rheumatoid arthritis or psoriatic arthritis treated with methotrexate and/or leflunomide. Ann Rheum Dis 69: 43-47.

24. Bird P, Griffiths H, Tymms K, Nicholls D, Roberts L, et al. (2013) The SMILE study -- safety of methotrexate in combination with leflunomide in rheumatoid arthritis. J Rheumatol 40: 228-235.

25. Mayall B, Poggi G, Parkin JD (1991) Neutropenia due to low-dose methotrexate therapy for psoriasis and rheumatoid arthritis may be fatal. Med J Aust 155: 480-484.
26. Bourré-Tessier J, Haraoui B (2010) Methotrexate drug interactions in the treatment of rheumatoid arthritis: a systematic review. J Rheumatol 37: 1416-1421.

27. Gutierrez-Ureña S, Molina JF, García CO, Cuéllar ML, Espinoza LR (1996) Pancytopenia secondary to methotrexate therapy in rheumatoid arthritis. Arthritis Rheum 39: 272-276.

28. Scott DL (2004) Interstitial lung disease and disease modifying antirheumatic drugs. Lancet 363: 1239-1240.

29. Kremer JM, Alarcón GS, Weinblatt ME, Kaymakcian MV, Macaluso M, et al. (1997) Clinical, laboratory, radiographic, and histopathologic features of methotrexate-associated lung injury in patients with rheumatoid arthritis: a multicenter study with literature review. Arthritis Rheum 40: 1829-1837.

30. Doran MF, Crowson CS, Pond GR, O'Fallon WM, Gabriel SE (2002) Frequency of infection in patients with rheumatoid arthritis compared with controls: a population-based study. Arthritis Rheum 46: 2287-2293.

31. Franklin J, Lunt M, Bunn D, Symmons D, Silman A (2007) Risk and predictors of infection leading to hospitalisation in a large primary-carederived cohort of patients with inflammatory polyarthritis. Ann Rheum Dis 66: 308-312.

32. van der Veen MJ, van der Heide A, Kruize AA, Bijlsma JW (1994) Infection rate and use of antibiotics in patients with rheumatoid arthritis treated with methotrexate. Ann Rheum Dis 53: 224-228.

33. Lacaille D, Guh DP, Abrahamowicz M, Anis AH, Esdaile JM (2008) Use of nonbiologic disease-modifying antirheumatic drugs and risk of infection in patients with rheumatoid arthritis. Arthritis Rheum 59: 1074-1081.

34. Smitten AL, Choi HK, Hochberg MC, Suissa S, Simon TA, et al. (2008) The risk of hospitalized infection in patients with rheumatoid arthritis. J Rheumatol 35: 387-393.

35. Coyne P, Hamilton J, Heycock C, Saravanan V, Coulson E, et al. (2007) Acute lower respiratory tract infections in patients with rheumatoid arthritis. J Rheumatol 34: 1832-1836.

36. Wolfe F, Caplan L, Michaud K (2006) Treatment for rheumatoid arthritis and the risk of hospitalization for pneumonia: associations with prednisone, disease-modifying antirheumatic drugs, and anti-tumor necrosis factor therapy. Arthritis Rheum 54: 628-634.

37. LeMense GP, Sahn SA (1994) Opportunistic infection during treatment with low dose methotrexate. Am J Respir Crit Care Med 150: 258-260.

38. Mercer LK, Davies R, Galloway JB, Low A, Lunt M, et al. (2013) Risk of cancer in patients receiving non-biologic disease-modifying therapy for rheumatoid arthritis compared with the UK general population. Rheumatology (Oxford) 52: 91-98.

39. Abásolo L, Júdez E, Descalzo MA, González-Alvaro I, Jover JA, et al. (2008) Cancer in rheumatoid arthritis: occurrence, mortality, and associated factors in a South European population. Semin Arthritis Rheum 37: 388-397.

40. Anderson LA, Pfeiffer RM, Landgren O, Gadalla S, Berndt SI, et al. (2009) Risks of myeloid malignancies in patients with autoimmune conditions. Br J Cancer 100: 822-828.

41. Bernatsky S, Clarke AE, Suissa S (2008) Hematologic malignant neoplasms after drug exposure in rheumatoid arthritis. Arch Intern Med 168: 378-381. 